Supplementary materials:

\title{
Effective Recycling of the Whole Cathode in Spent Lithium Ion \\ Batteries: from the Widely Used Oxides to High-Energy/Stable
}

\section{Phosphates}

Yang Yang ${ }^{\dagger}$, Jin-Zhi Guo ${ }^{\dagger}$, Zhen-Yi Gut, Zhong-Hui Sun" , Bao-Hua Hou ${ }^{\dagger}$, Ai-Bo Yang ${ }^{\dagger}$, Qiu- $^{\dagger}$ Li Ning ${ }^{\dagger}$, Wen-Hao Li ${ }^{\dagger}$, Xing-Long Wu*广t

† National \& Local United Engineering Laboratory for Power Batteries, Faculty of Chemistry, Northeast Normal University, Changchun, Jilin 130024, P. R. China

* Key Laboratory for UV Light-Emitting Materials and Technology, Northeast Normal

University, Ministry of Education, Changchun, Jilin 130024, P. R. China

${ }^{I I}$ Center for Advanced Analytical Science, clo School of Chemistry and Chemical Engineering, c/o MOE Key Laboratory for Water Quality and Conservation of the Pearl River Delta, Guangzhou University, Guangzhou, Guangdong 510006, P. R. China

*The corresponding author, E-mail: xinglong@nenu.edu.cn 


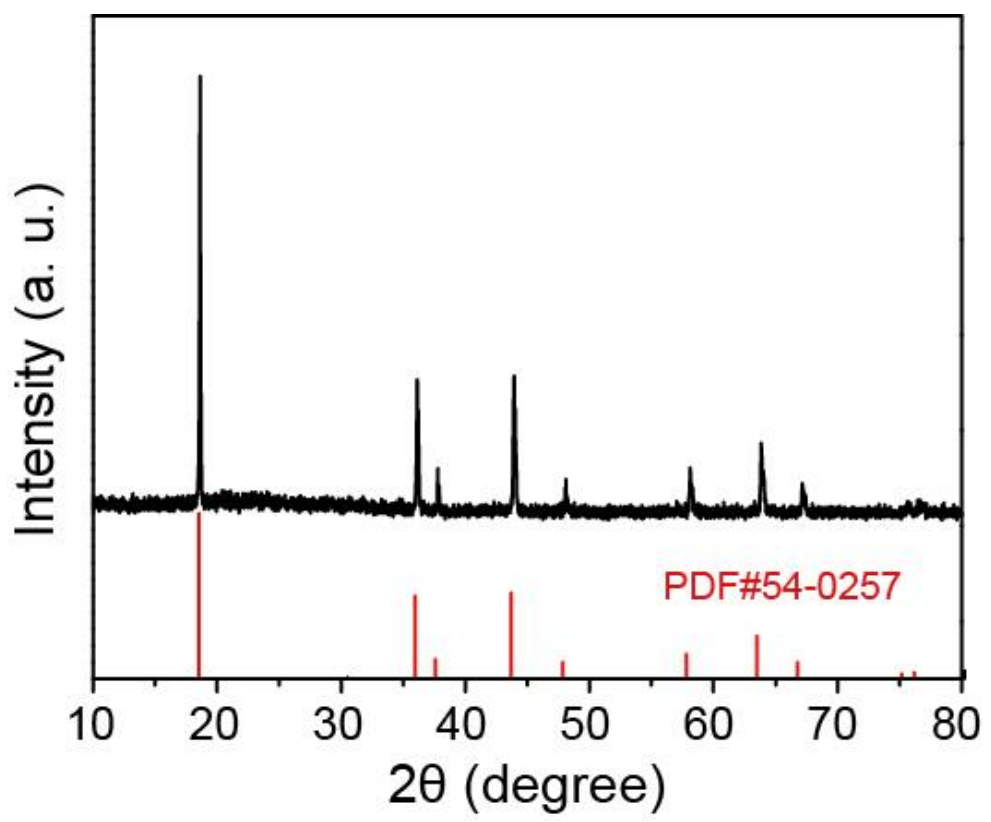

Figure S1 XRD pattern of $\mathrm{LiMn}_{2} \mathrm{O}_{4}$ electrode powders scraped directly from the spent $\mathrm{LiMn}_{2} \mathrm{O}_{4}$ lithium ion batteries.

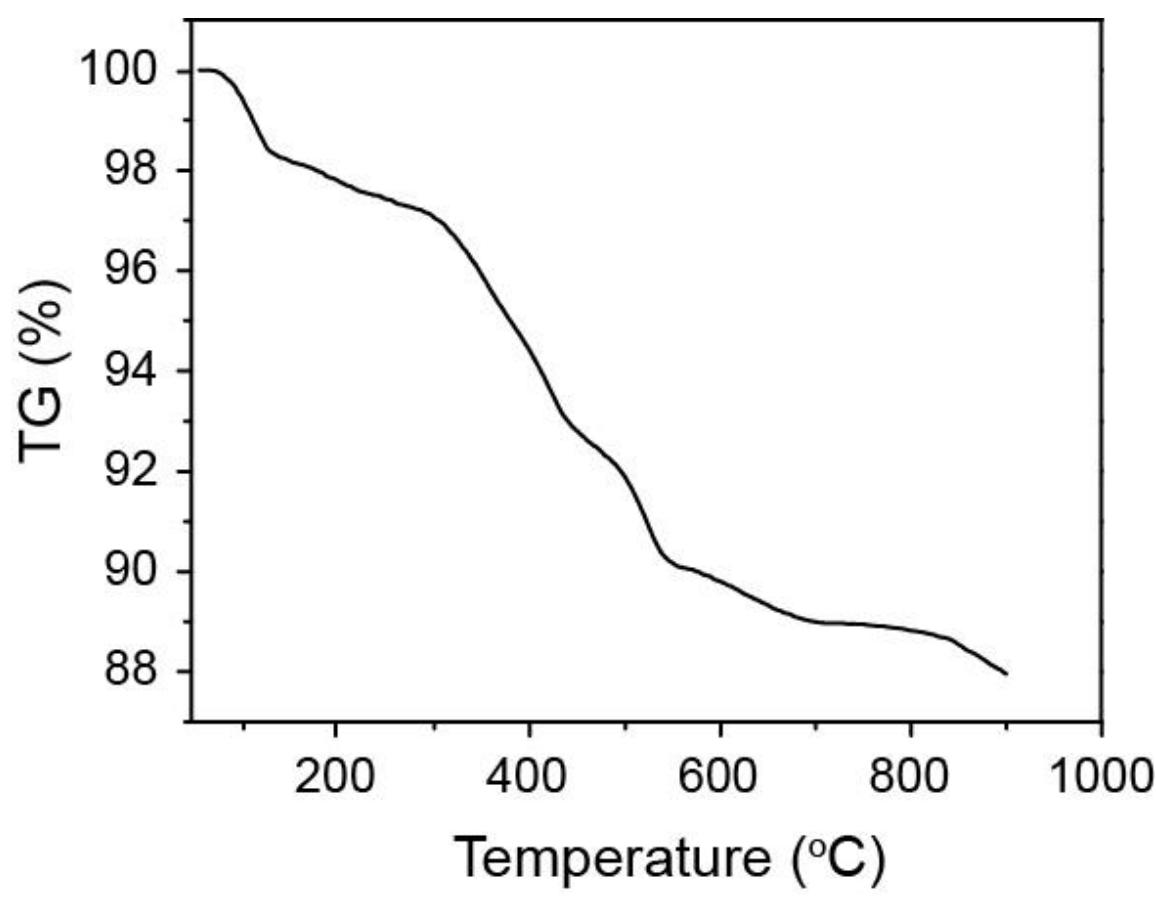

Figure S2 TG curves of the $\mathrm{LiMn}_{2} \mathrm{O}_{4}$ cathode electrode powders scraped directly from cathode plate. 
a

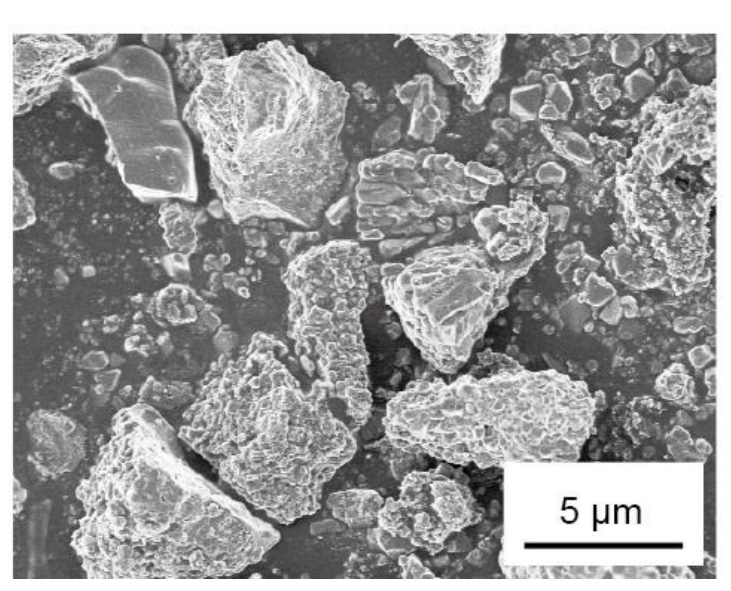

b

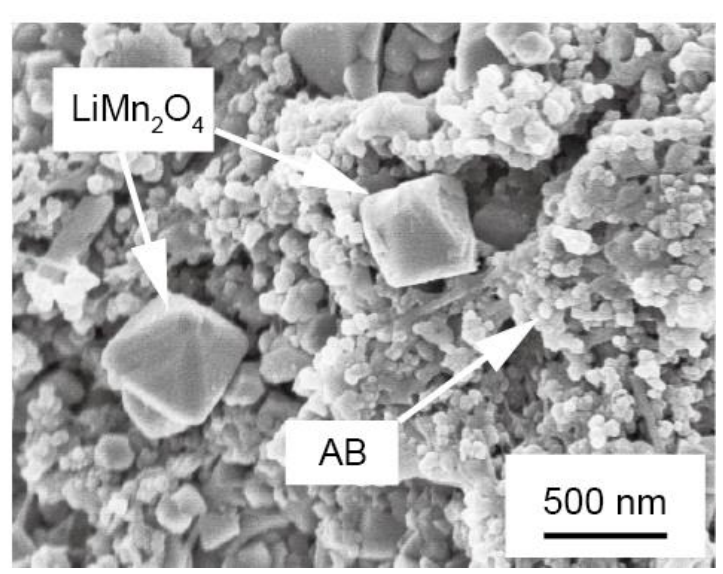

Figure S3 SEM images of $\mathrm{LiMn}_{2} \mathrm{O}_{4}$ cathode powders scraped directly from cathode plate. 

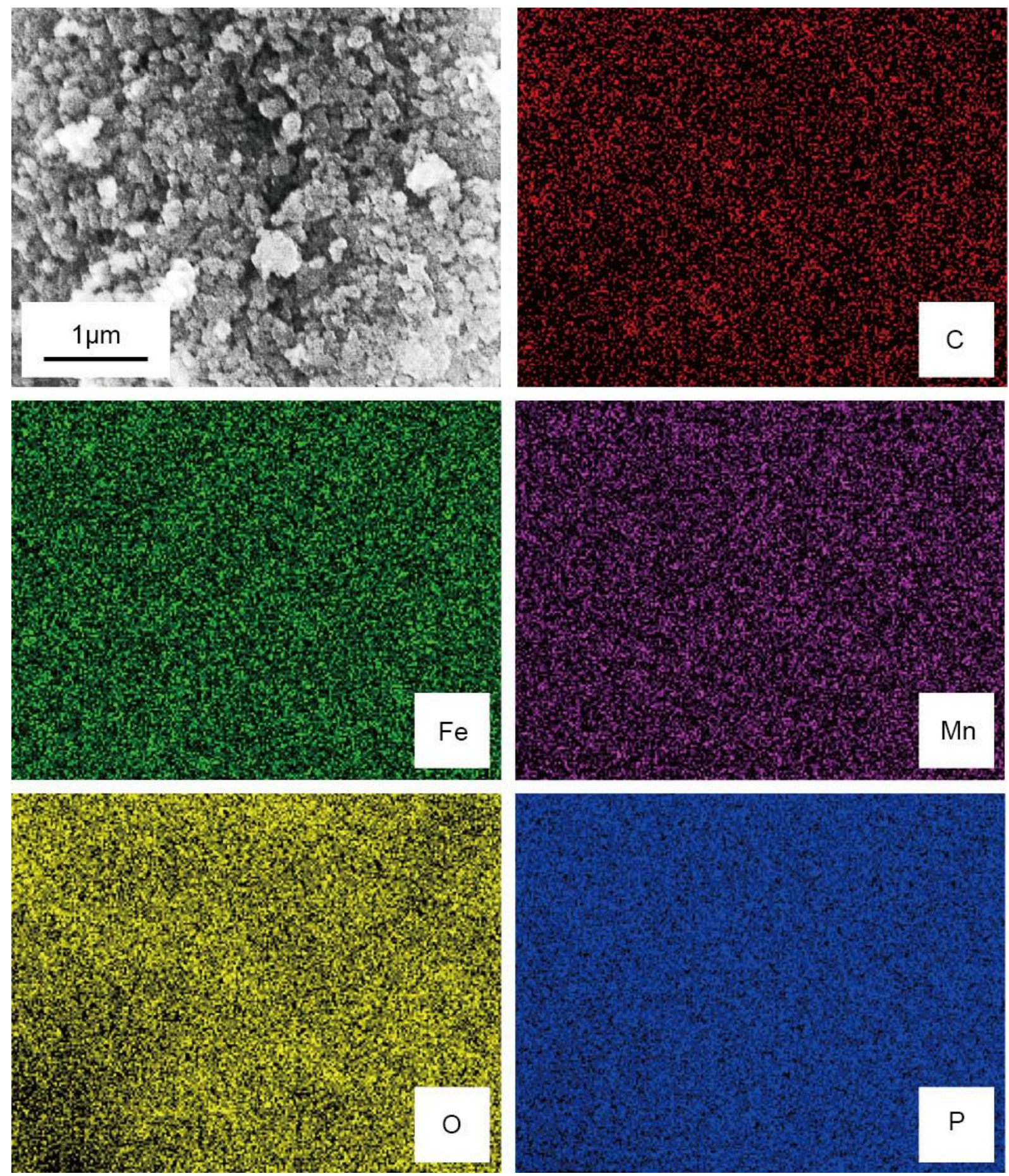

Figure S4 Elements mapping images of the regenerated $\mathrm{LiFe}_{0.6} \mathrm{Mn}_{0.4} \mathrm{PO}_{4}$. 

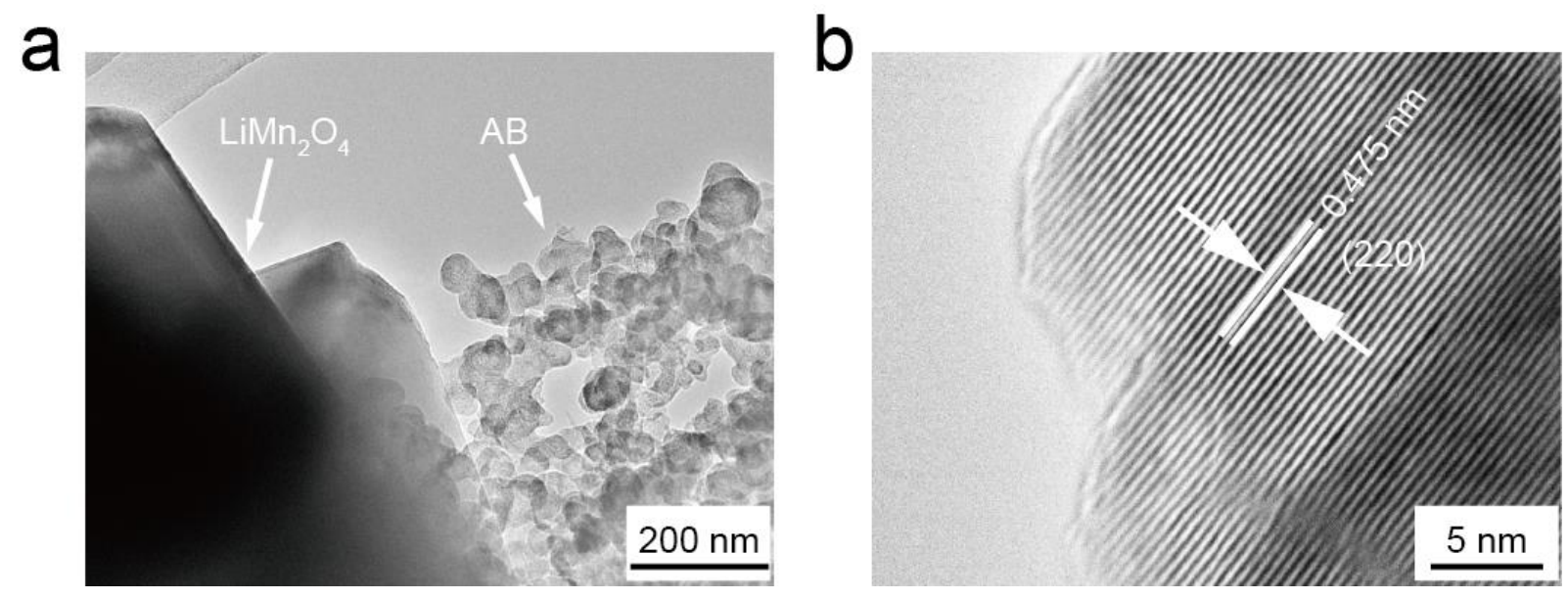

Figure S5 (a) TEM image of $\mathrm{LiMn}_{2} \mathrm{O}_{4}$ cathode powders scraped directly from cathode plate,

(b) HTEM image of the $\mathrm{LiMn}_{2} \mathrm{O}_{4}$ powders. 

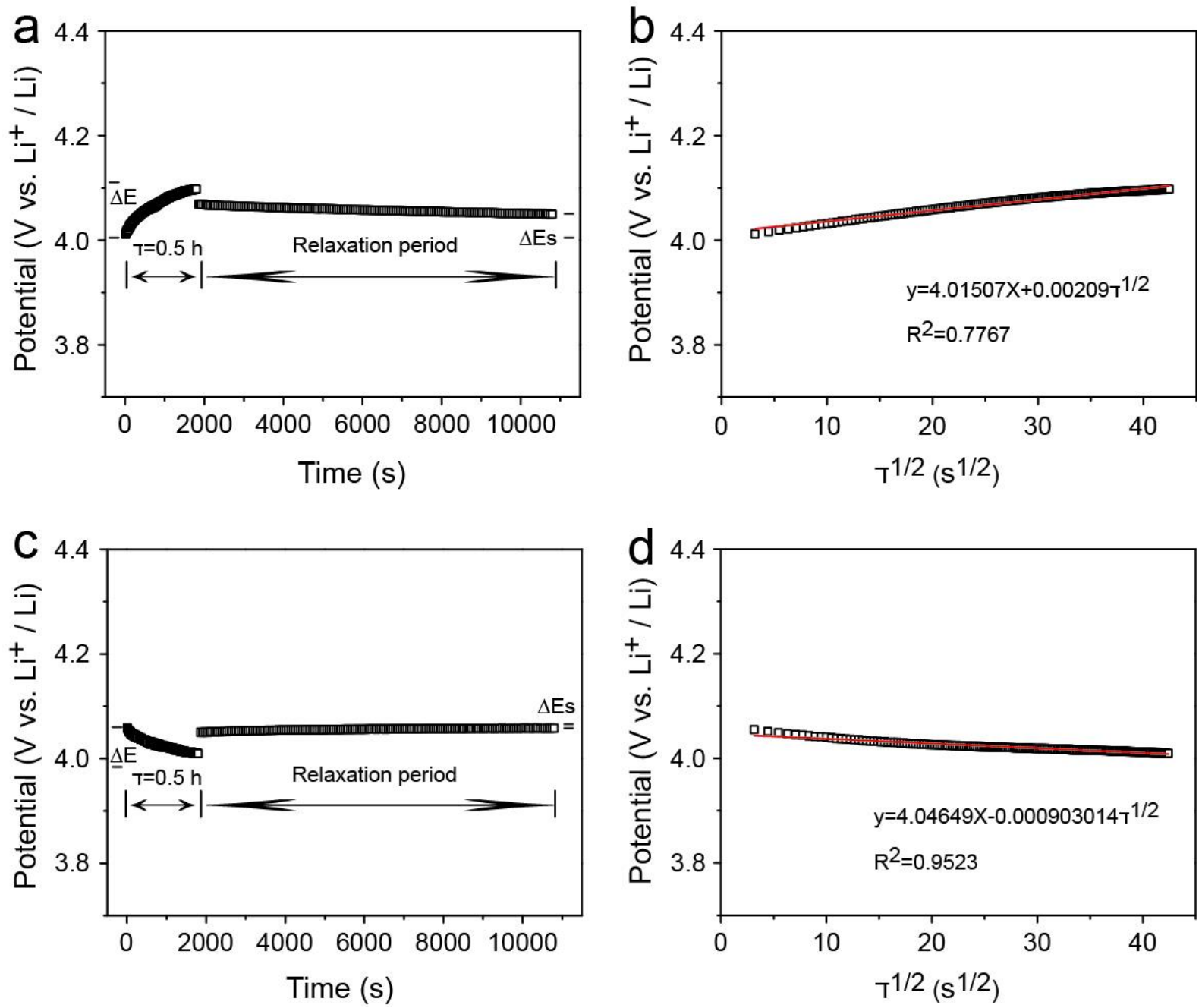

Figure S6 A single GITT profile for charge and discharge process. $\tau$ vs. E profiles for a single GITT titration during (a) charge and (c) discharge processes. The corresponding linearly fitting behavior of E vs. $\tau^{1 / 2}$ for the (b) charge and (d) discharge GITT titration. 

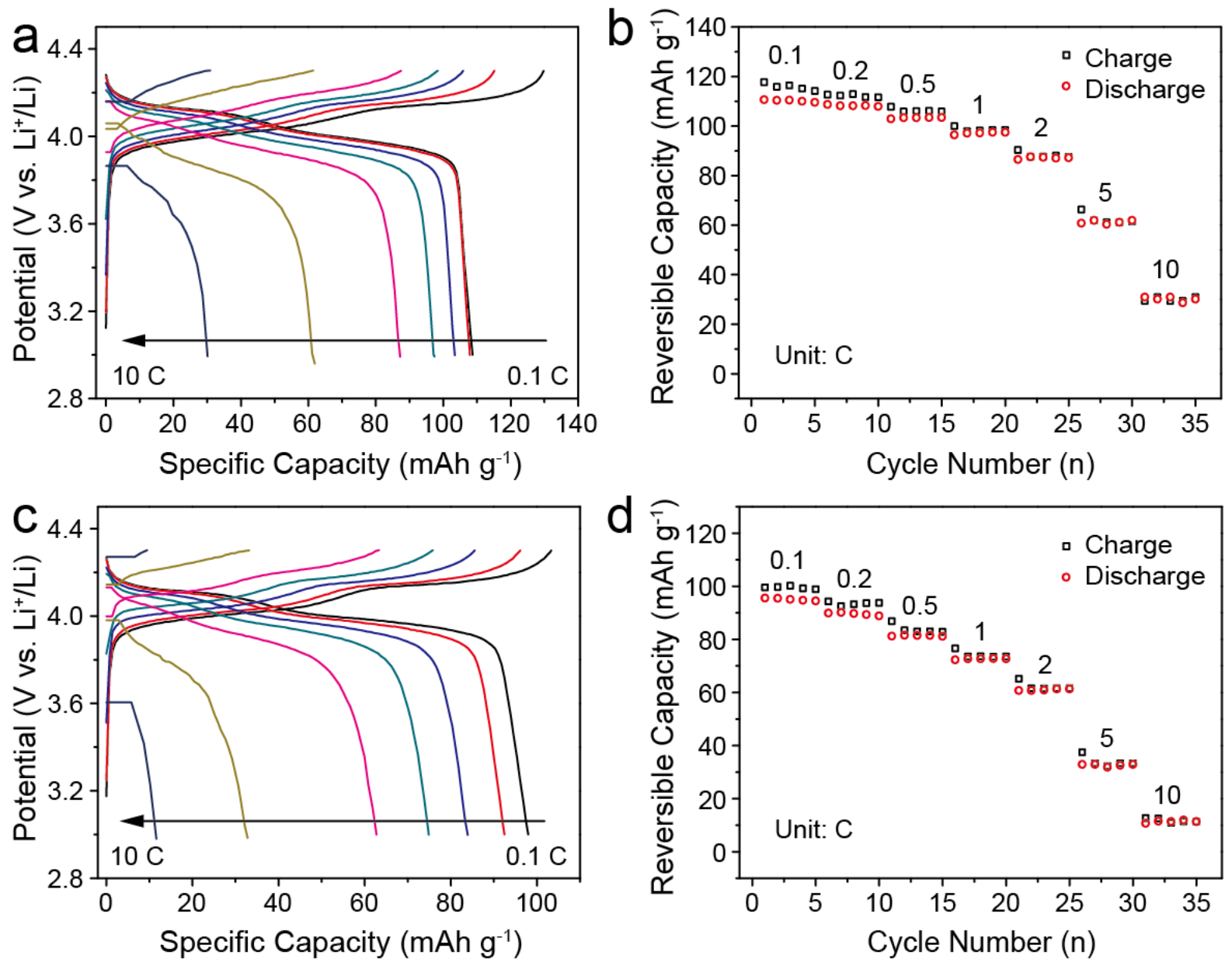

Figure S7 (a) Charge/discharge profiles of pristine $\mathrm{LiMn}_{2} \mathrm{O}_{4}$ cathode at different rate between 0.1 - $10 \mathrm{C}$, (b) rate capabilities of pristine $\mathrm{LiMn}_{2} \mathrm{O}_{4}$ from $0.1 \mathrm{C}$ to $10 \mathrm{C}$, (c) Charge/discharge profiles of spent $\mathrm{LiMn}_{2} \mathrm{O}_{4}$ cathode at different rate between $0.1-10 \mathrm{C}$, (d) rate capabilities of spent $\mathrm{LiMn}_{2} \mathrm{O}_{4}$ from $0.1 \mathrm{C}$ to $10 \mathrm{C}$. 


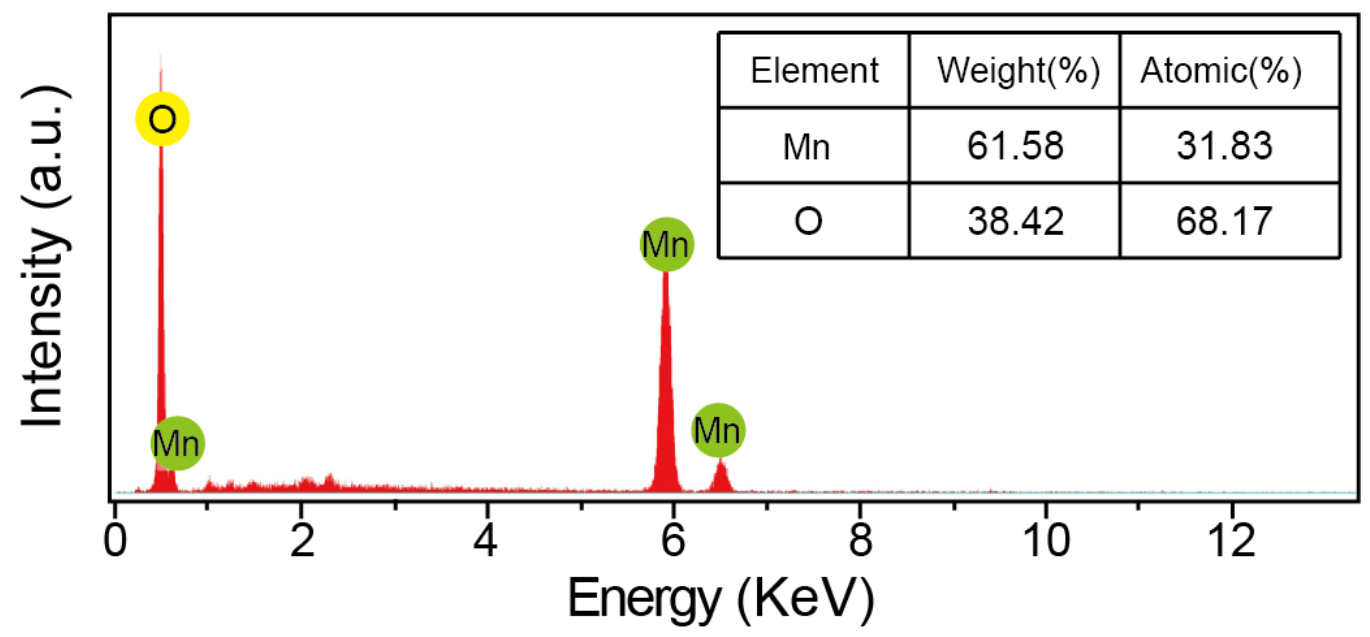

Figure S8 The EDS image of pristine $\mathrm{LiMn}_{2} \mathrm{O}_{4}$.

Table S1 The ICP test result of $\mathrm{Li}$ and $\mathrm{Mn}$ in the prinst $\mathrm{LiMn}_{2} \mathrm{O}_{4}$.

\begin{tabular}{|c|c|c|}
\hline & $\begin{array}{c}\text { Measured } \\
\text { concentration }(\mu \mathrm{g} / \mathrm{ml})\end{array}$ & Measured atomic ratio \\
\hline Mn & 53.920179 & 4.90 \\
\hline $\mathrm{Li}$ & 4.087301 & 2.95 \\
\hline
\end{tabular}

Table S2 The ICP test result of $\mathrm{Li}$ and $\mathrm{Mn}$ in the spent $\mathrm{LiMn}_{2} \mathrm{O}_{4}$.

\begin{tabular}{|c|c|c|}
\hline & $\begin{array}{c}\text { Measured } \\
\text { concentration }(\mu \mathrm{g} / \mathrm{ml})\end{array}$ & Measured atomic ratio \\
\hline $\mathrm{Mn}$ & 47.557992 & 4.32 \\
\hline $\mathrm{Li}$ & 3.805562 & 2.75 \\
\hline
\end{tabular}


Table S3 The ICP test results of spent $\mathrm{LiMn}_{2} \mathrm{O}_{4}$ and $\mathrm{LiMn}_{0.4} \mathrm{Fe}_{0.6} \mathrm{PO}_{4}$

\begin{tabular}{|c|c|c|}
\hline & $\begin{array}{c}\text { Measured } \\
\text { concentration (\%) } \\
\text { in spent LMO }\end{array}$ & $\begin{array}{c}\text { Measured } \\
\text { concentration (\%) } \\
\text { in LMFP }\end{array}$ \\
\hline $\mathrm{Al}$ & $\mathbf{0 . 1 9}$ & $\mathbf{0 . 0 7 2}$ \\
\hline $\mathrm{Cr}$ & $\mathbf{0 . 0 0 3 4}$ & $\mathbf{0 . 0 7 1}$ \\
\hline $\mathrm{Cu}$ & $\mathbf{0 . 0 0 5 3}$ & $\mathbf{0 . 2 4}$ \\
\hline $\mathrm{Ni}$ & $\mathbf{0 . 0 4 5}$ & $\mathbf{0 . 0 2 2}$ \\
\hline $\mathrm{K}$ & $\mathbf{0 . 0 5 6}$ & $\mathbf{0 . 0 8 7}$ \\
\hline $\mathrm{Na}$ & $\mathbf{0 . 2 5}$ & $\mathbf{0 . 1 9}$ \\
\hline $\mathrm{Ca}$ & $\mathbf{0 . 1 5}$ & $\mathbf{0 . 2 3}$ \\
\hline $\mathrm{Mg}$ & $\mathbf{0 . 0 6 1}$ & $\mathbf{0 . 0 2 2}$ \\
\hline
\end{tabular}

Calculation process for the apparent Li chemical diffusion coefficients through CV tests.

The apparent Li diffusion coefficient $\left(\mathrm{D}_{\mathrm{app}, \mathrm{Li}}\right)$ was calculated from following RandlesSevcik equation:

$i_{p}=2.69 \times 10^{5} n^{3 / 2} A D_{a p p, L i}{ }^{1 / 2} C_{0} v^{1 / 2}$

Where $i_{\mathrm{p}}$ is the peak current density, $\mathrm{n}$ is the electron-transfer number per molecule formula during the redox reaction ( $\mathrm{n}=1$ for the present $\mathrm{LFMP} / \mathrm{C}$ ), $\mathrm{A}$ is the surface area of the electrode, $\mathrm{C}_{0}$ is the concentration of $\mathrm{Li}$ ions in the electrode $\left(2.27 \times 10^{-2} \mathrm{~mol} / \mathrm{cm}^{3}\right)$, and $v$ is the scan rate.

\section{Calculation process for the apparent Li chemical diffusion coefficients through GITT} tests.

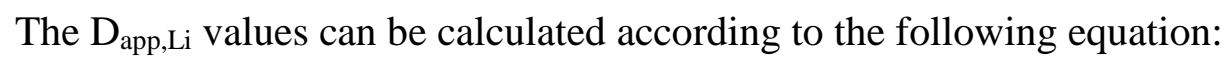

$D_{a p p, L i}=\frac{4}{\pi \tau}\left(\frac{m_{B} V_{M}}{M_{B} S}\right)^{2}\left(\frac{\Delta E_{S}}{\Delta E_{\tau}}\right)^{2} \quad \tau \ll L^{2} / D$

Where $m_{B}, M_{B}$, and $V_{M}$ are the mass, molecular weight, and molar volume of the LFMP/C material, respectively, $\tau$ is the time for an applied galvanostatic current, $S$ is the active surface of the electrode, $\mathrm{L}$ is the average radius of the material particles, and $\Delta \mathrm{E}_{\mathrm{s}}$ and $\Delta \mathrm{E}_{\tau}$ are the 
quasi-equilibrium potential and the change of cell voltage $\mathrm{E}$ during the current pulse, respectively. 